\title{
Malfunction crack failure in hydrodynamically lubricated bearings: A Case Study Hydraulic Turbine
}

\author{
Yahya Taşgin ${ }^{1}$ and Gökhan Kahraman ${ }^{1}$ \\ ${ }^{1}$ Munzur Universitesi
}

April 28, 2020

\begin{abstract}
This study investigates the trunnion crack of a $50 \mathrm{MW}$ hydraulic turbine in the generator guide bearing. The crack area has been examined metallographically and the fixing method for the the trunnion crack has been explained. Result of the study shows that the reason for the formation of the bearing trunnion crack can be the thermal stresses that occur during the mounting of the bearing trunnion to the turbine shaft and the material fatigue that occurs during the operation of the hydraulic turbine.
\end{abstract}

\section{Introduction}

There are many risks in hydroelectric power plants. Analyzing these risks and taking precautions will provide the biggest contribution to the power plant in order to be ready for continuous energy production [1]. One of the most important of these risks is the failure of the turbines-generator units' sliding bearing of hydroelectric power plants. The safe operation of the turbine-generator units of hydroelectric power plants depends to a great extent on the safe and sound operation of hydrodynamic lubricated bearings. Therefore, the standard size of the bearing gaps, the ideal viscosity value of the bearing oil and a good bearing oil cooling system are very important in the bearings of the hydraulic turbine-generator units. There are many studies in the literature on hydrodynamic lubrication bearings $[2,3,4,5]$. One of the most important parts of hydrodynamic lubrication bearings is bearing shells. The bearing shells work together with the bearing pads by forming the oil film and carry a large amount of axial or radial loads. These very sensitive working conditions require very precise machining of the surfaces of the bearing shells and pads. In most cases, there are fractures in the bearing shells due to material faults and this failure prevents the turbines of hydroelectric power plants from producing electricity for a long time and causes great financial losses. Metal fractures may be caused by many reasons. Fatigue fracturing damage is often dealt with under cyclic loading, but it is also important to assess the under monotonic overload condition. This is due to the fact that fatigue fracturing increases the strength of the structure under certain conditions [6]. Two boundary conditions are taken into account for fracture structures: The Ultimate-Mate Limit State (ULS) and the Fatigue Limit State (FLS). The final boundary state corresponds to the maximum load-bearing capacity that takes into account the monotonic loading, whereas the fatigue boundary state corresponds to deterioration due to the effect of the cyclic loading over time [7]. Da-wei et al. have analyzed the ultimate strength of fracture progression in two different categories of research on the ultimate strength of fractured structures. Fractures in materials are often seen as a result of impact and welded areas, accidental overloading can potentially lead to fracturing. The onset of fractures may also be caused by the effect of repeated loads in stress concentration zones. If such initial fracturing is left undetected or not immediately repaired, it may turn into a fracturing that continues to spread under repeated loads, thus causing an aging regimen [8]. When a fracture is spread, the material tearing events in areas near the fractures are slightly larger. In the final power analysis, the mechanical properties of the structural elements are considered rather than the fracture end. Therefore, material tearing events can be seen as fracture propagation criteria [9]. Paik has performed a series of tensile 
and compression tests on plates with predetermined fracturing damage. He has investigated the effects of different geometric parameters on the final strength of the boards such as fracture length, crevasse, gap between fractures, fracture size and plate thickness [10].

Seifi and Khoda Yari have conducted an experimental research on plates with three different aspect ratios. They have evaluated the results by taking into account the fixed plate length and different aspect ratios obtained with variable widths. For plates with equal fracture length (the ratio of fracture length to plate width), they have concluded that the buckling load was proportional to the plate size ratio [11].

$\mathrm{Hu}$ et al. have examined the final tensile/compressive strength of unhardened and hardened plates. In addition to their material strength and fracture length, they have mentioned a parameter that influenced the softness of the plate and the final compressive strength [9]. Paik, et al. have stated that if the fracture size exceeds a critical fracture length, a fractured plate reaches the final boundary state. They assess the triple fracture length as a criterion for evaluating fracture progression [12]. Babazadeh and Khedmati have said final strength of fractured plate are affected by the fracture length, orientation and location. They have examined how these parameters affect plate behavior. As a result of a study on the final strength of fractured plates and the results of research in this area, the fracture length it is understood that it had the most important effect on the final strength of the plates [13]. At the same time, since the fracturing orientation changes in the longitudinal direction (perpendicular to the loading) in the transverse direction, the impact of the fracture on the highest strength of the plates becomes negligible [14].

Paik and Thayamballi have performed a series of tensile and compression tests on pre-fractured plates. They investigate the effects of different geometric parameters, such as fracture length, fracture position, gap size between fracture faces, and plate thicknesses on the final strength of the plates. The test specimen is box-type coating structures comprising a pre-broken fracture obtained by welding four similar steel plate adhesions as mounting. They have presented the results as stress curves [15]. Rycerz ve diğerleri, yatak yüzeylerinde yorulma sonucu oluşan çatlakların yayılmasını incelemişlerdir. Inceleme sonucunda, gözlenen çatlak morfolojisi, mühendislik bileşenlerinde bulunan ve literatürde rapor edilen, yüzeydeki v-şekilli görünüm, yüzeye $20-30^{\circ}$ eğim açısı ve sürtünme kuvvetinin yönüne doğru yayılma dahil olmak üzere, tipik RCF çatlaklarının tüm özelliklerini sergilemiştir[16]. Maya ve diğerleri, iki perlitli yay çeliğinin yorulma çatlağı büyüme oranını incelemişlerdir. İnceleme sonucunda her iki ray çeliğinde perlitin daha küçük interlaminar aralığı düşük değerleri için yorulma çatlağı büyüme oranında bir azalmaya yol açtığını belirtmişlerdir[17].

The fracture origin is caused by a fatigue mechanism with surface defect [18]. Although some authors have reported a change in final strength about the fracture position, it can be said that there is not a significant influence on the final strength of the longitudinal and transverse locations of the fracture in general. [19]. The stress is very sensitive to material defects that provide strain points that can initiate stretch fractures [20].

\section{Material and Method}

The bearings used in turbine-generator units of hydroelectric power plants are called sliding bearing. Sliding bearings are divided into hydrodynamic and hydrostatic. The hydrodynamic bed oil film is formed spontaneously. On the hydrostatic bed, an oil pump from the outside supports the bearing oil. The bearing shells work together with the bearing pad. The oil film formed between the bearing shell and the bearing pad has very large radial or axial loads depending on the position of the rotating mass. Figure 1 is a schematic view of the bearings in the Francis turbine of a hydropower plant with a vertical shaft. 


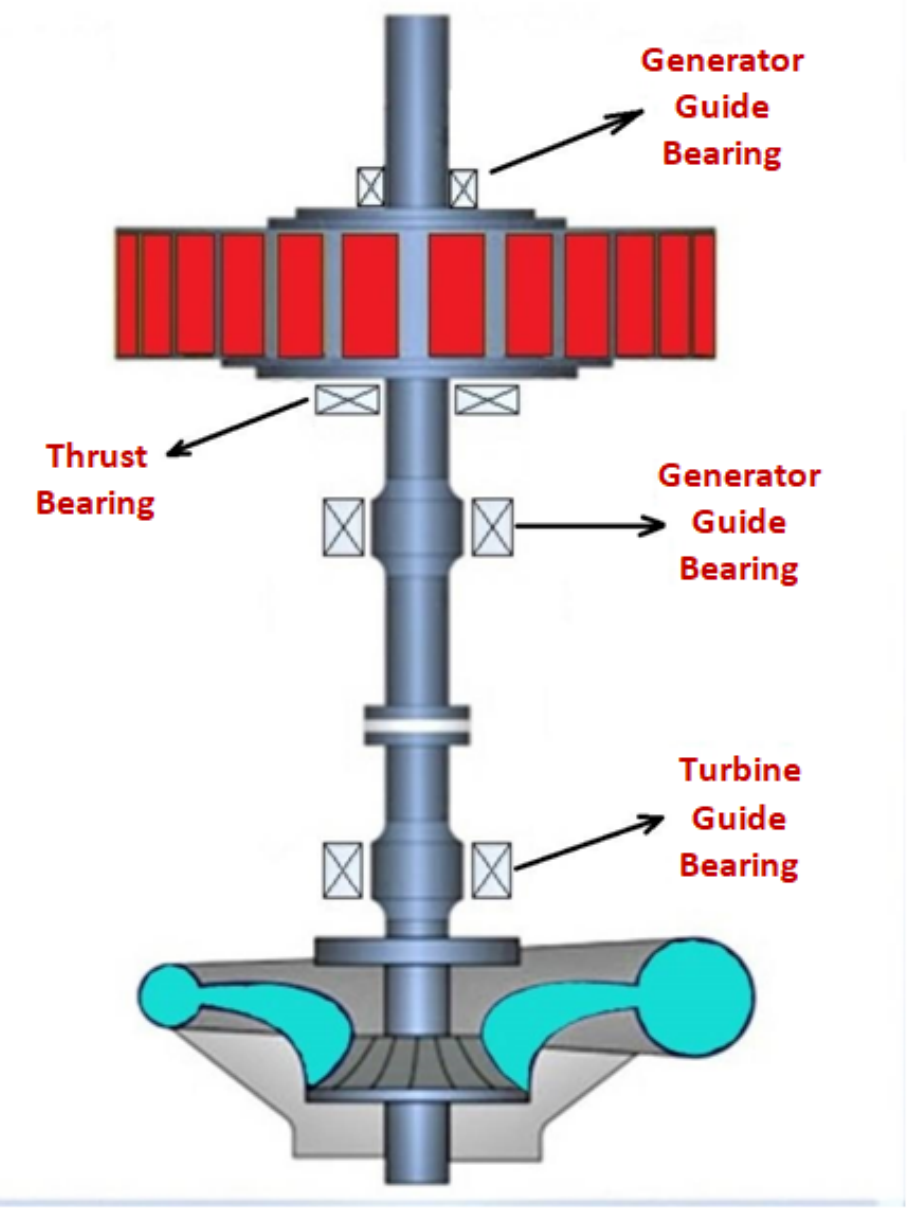

Figure 1. Schematic representation of the sliding bearings used in turbine-generator units of hydroelectric power plants

The lubrication must be perfect for a sliding bed to operate safely. In order to prevent warming and surface deterioration caused by the friction of the bearing surface, the sliding surfaces must be completely separated from each other by the oil film and the liquid friction event must take place. In order to realize the fluid friction in the sliding bearings, the conditions given below should be met by using hydrodynamic lubrication theory.

* There must be a gap in the direction of movement between the sliding bearing shell and pad.

* The sliding surfaces must be relative to each other.

* Lubricating oil should be able to show very good adhesion on the sliding surfaces.

* The sliding bearing and the pad surfaces must be processed in very good quality.

If one of the above mentioned points is not applied carefully, the oil film ruptures occur, causing major damage to the turbine generator bearing system.

In the fractures in the sliding bearing shell, it disrupts the theory of hydrodynamic lubrication and causes the oil film to rupture. The bearing shell fracture in the generator guide bearing of a hydroelectric power 
plant is shown in Figure 2
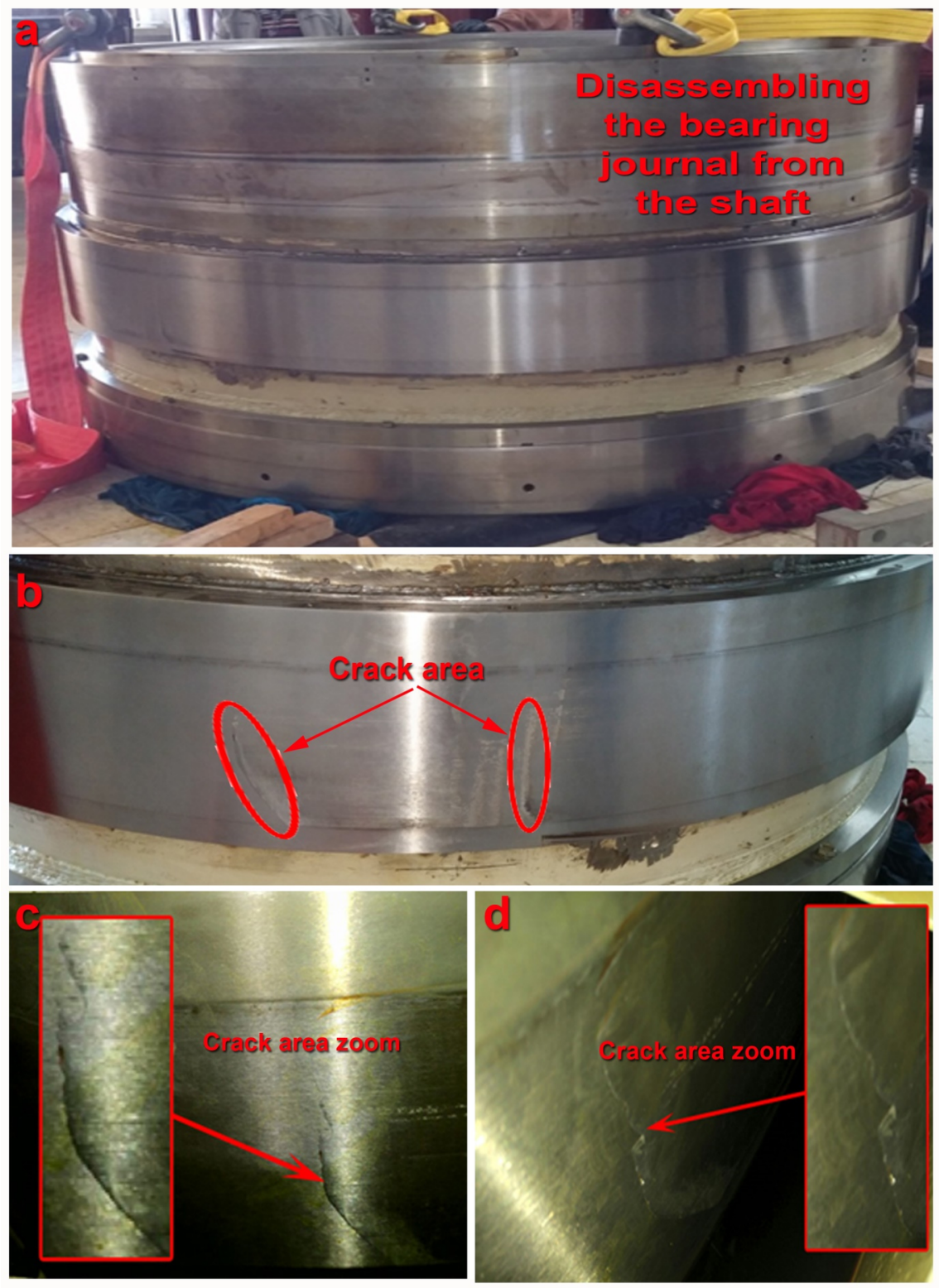

Figure 2. Image of crack areas on the bearing trunnion

As can be seen in Figure 2, the fracture in sliding bearing shell has reached the level to prevent the efficient operation of the bearing. In addition, the fracture seen in figure 2 continues to progress. Differences in the values of the vibration sensor connected to the turbine generator unit were interpreted and the generator guide bearing area was disassembled and fixed on the fracture bearing shell and the fault clearance studies were initiated without causing major damage to the bearing.

Figure 3 shows the repair stages of the crack area. 


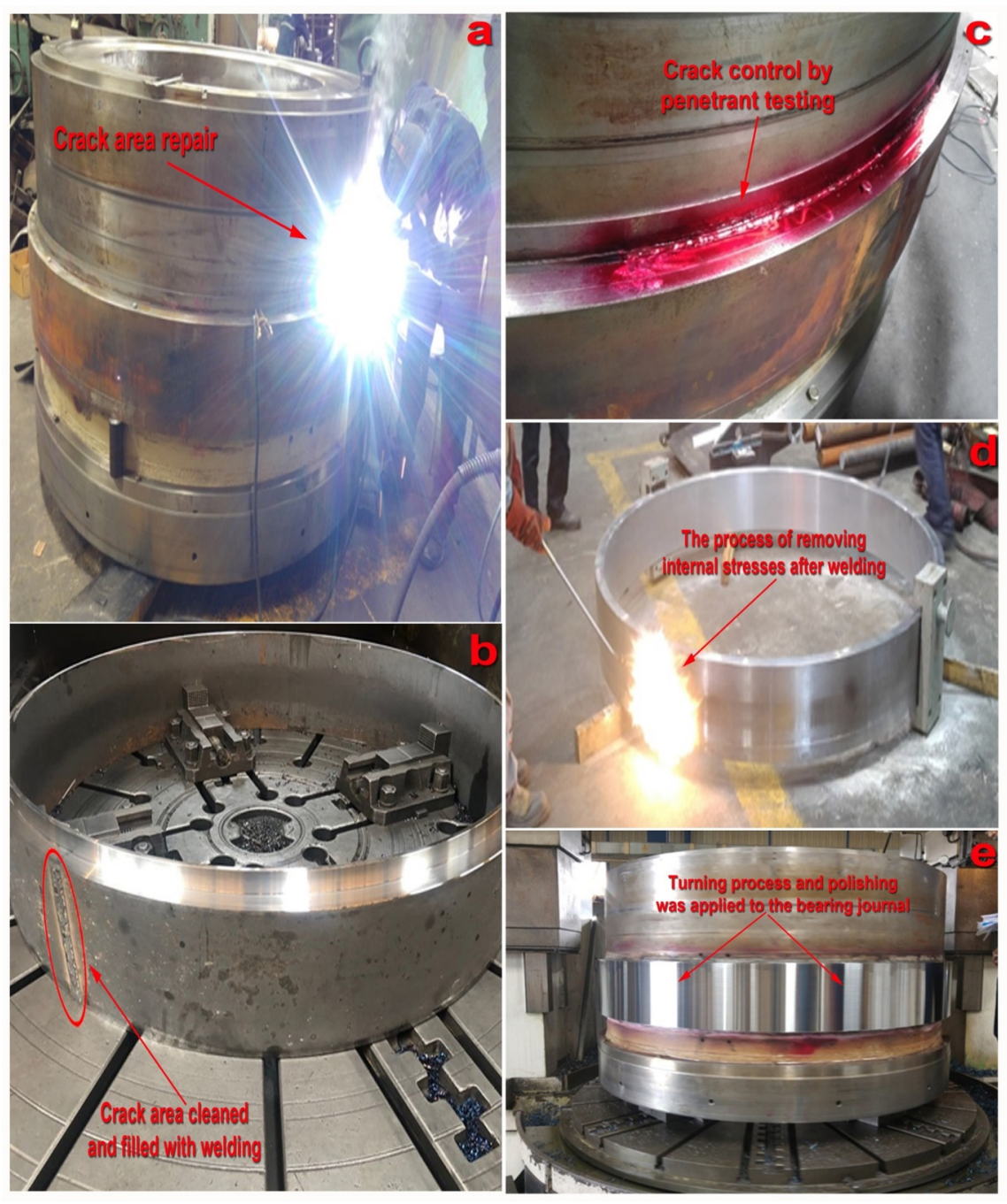

Figure 3.a) Repair of crack areas with oxyacetylene welding b) Cracks filled with weld c) Penetrant test for crack control d) Heat treatment on journal surface e) Turning and grinding process

\section{Metallographic Investigation of Fractured Bearing Shell}

When the metallographic analysis of the causes of fractureing in the generator guide bearing shell ring used in the bearing of the shaft in hydroelectric power plants, it was observed that the material was a low carbon steel when the analysis results were taken into consideration. The internal structure of this type of steel changes depending on the carbon content and heat treatment. Also, the use and environmental conditions are among the factors affecting the structure.

As a result of the metallographic studies carried out on the sample, we received from the area near the fracture of the fracture formation, in the optical images given in Figure 3, it is seen that the main structure (Matrix) is composed of ferrite (yellow regions), and the black regions which are scattered in the structure are perlite.

As a result of the metallographic studies applied on the sample taken from the area near the crack formation, it is considered that the progress is slow due to the thin and regular ferritic structure of the material. It is possible that the progress of the crack along the grain boundaries may be caused by dislocation within 
the structure. It is clear that the main structure (Matrix) is composed of ferrite (yellow areas), and the black areas that are scattered within the structure are perlite, and there are ferrite and cementite structures within the perlite structure.

When we examine the SEM images in the different magnifications given in Figure 4, it was observed that the black regions are the main structure of the ferrite, the white areas seen as lines and layers are perlite and the structure seen as the lines is composed of the cementite forming the perlite.

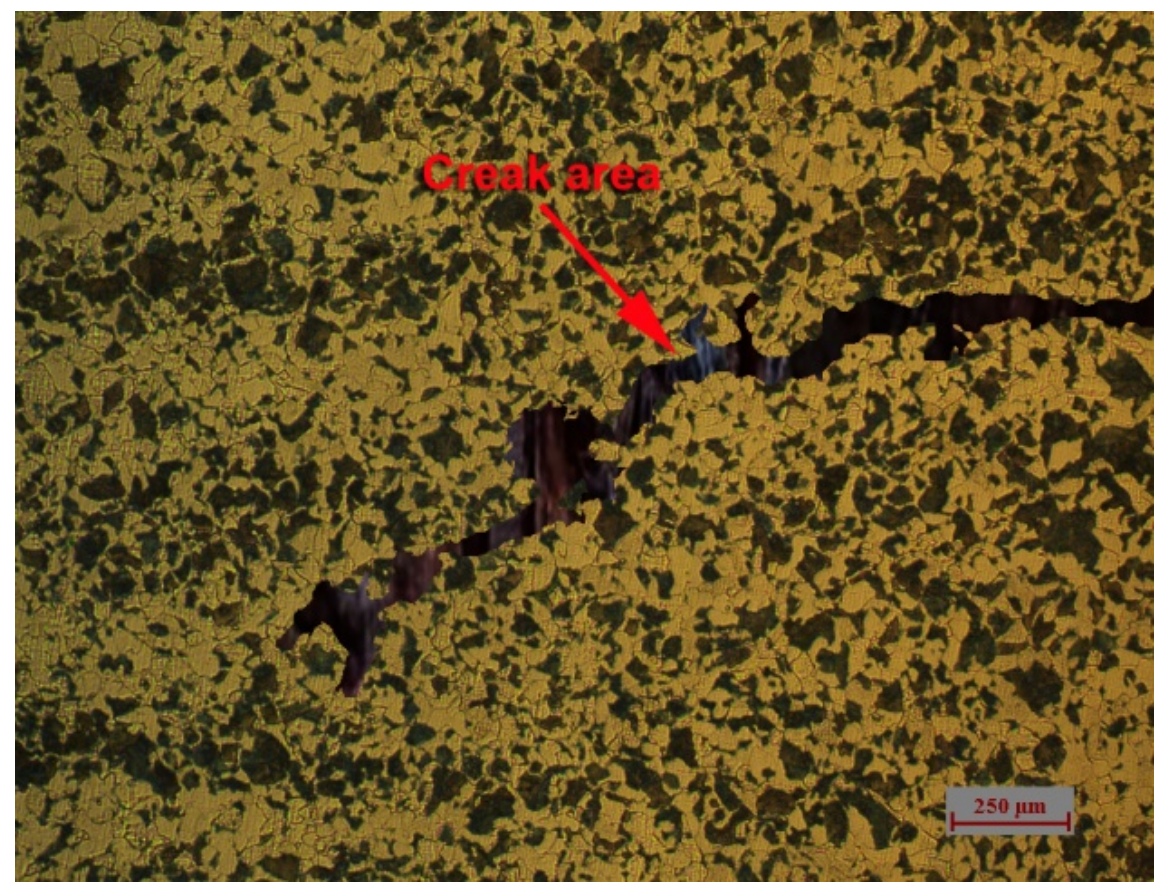




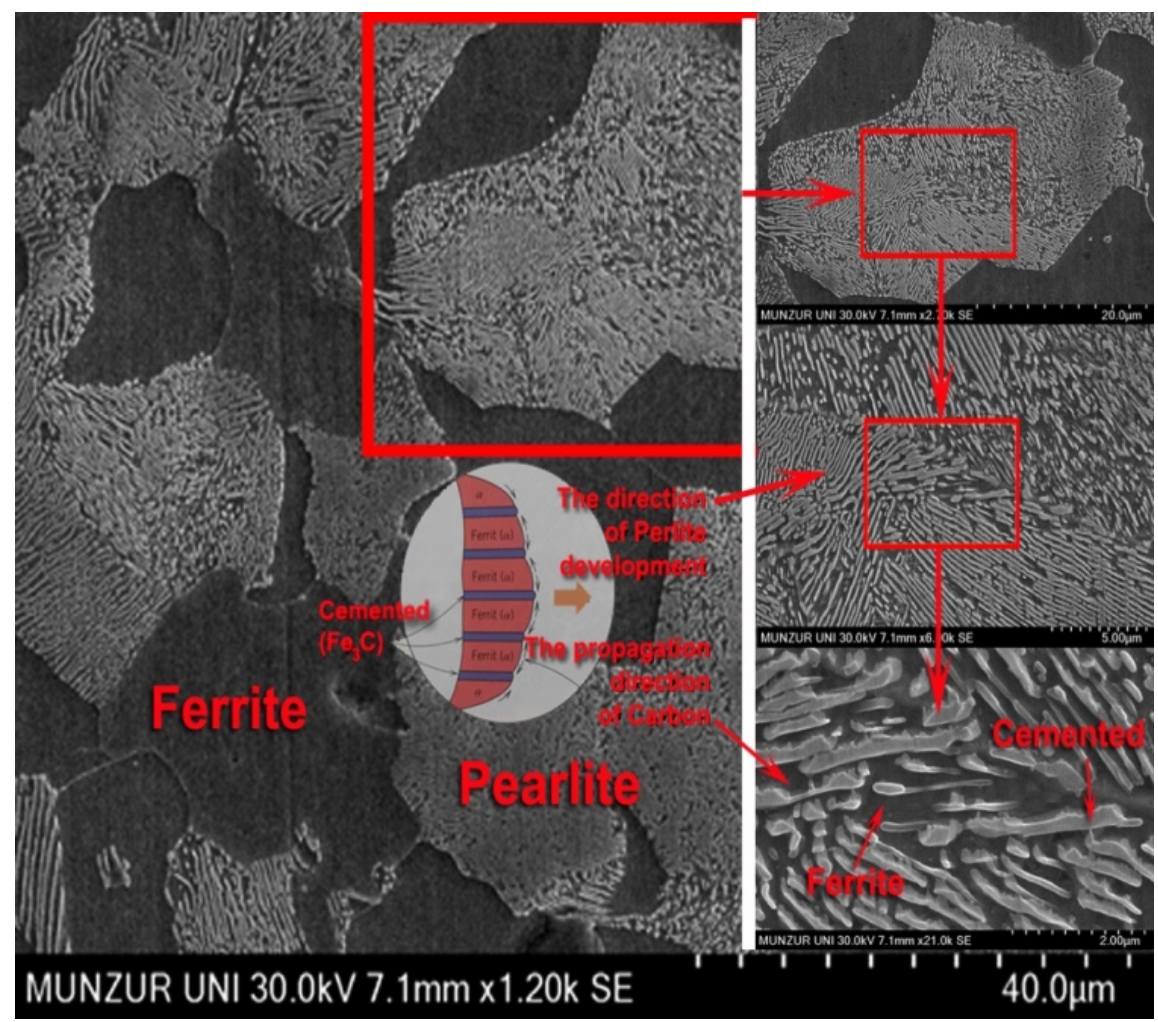

Figure 4.a) Optical images at different magnifications taken from the fractured region of the bearing shell material. b) SEM

Cementite $\left(\mathrm{Fe}_{3} \mathrm{C}\right)$ is formed when the solubility limit of $\alpha$ ferrite phase $\mathrm{C}$ below $727{ }^{0} \mathrm{C}$ is exceeded. In terms of mechanical properties, cementite is very hard and brittle and plays an important role in strengthening the structure of steel. The cementite can remain compound at room temperature for half-stable indefinitely, but when it is subjected to aging heat treatment, it converts to $\alpha$ ferrite and graphite.

The structure formed by the combination of $\alpha$ ferrite and $\mathrm{Fe}_{3} \mathrm{C}$ layers (Lamels) is called perlite repeating one by one as a result of slow cooling of the steels. Due to its ferrite and cementite structure, perlite is more ductile, it has mechanical properties such as ferritic structure and harder and brittle cementite phase.

Figure 6 and 7 shows the EDS analysis that we have taken from the whole of the material and some parts of it. In the analysis we received from the overall structure, the distribution in the structure was better observed by making different coloring for each metal alloy. As a result of EDS analysis it is seen that the matrix consists of $96.93 \% \mathrm{Fe}$ and other elements are in small amounts.

When we examine the spectrum peaks obtained from the EDS analysis, the two compounds come to the fore: in addition to compounds consisting of $\mathrm{C}, \mathrm{Mn}$ and $\mathrm{Si}$, compounds consisting of $\mathrm{Fe}$ and $\mathrm{Mn}$ are observed. 


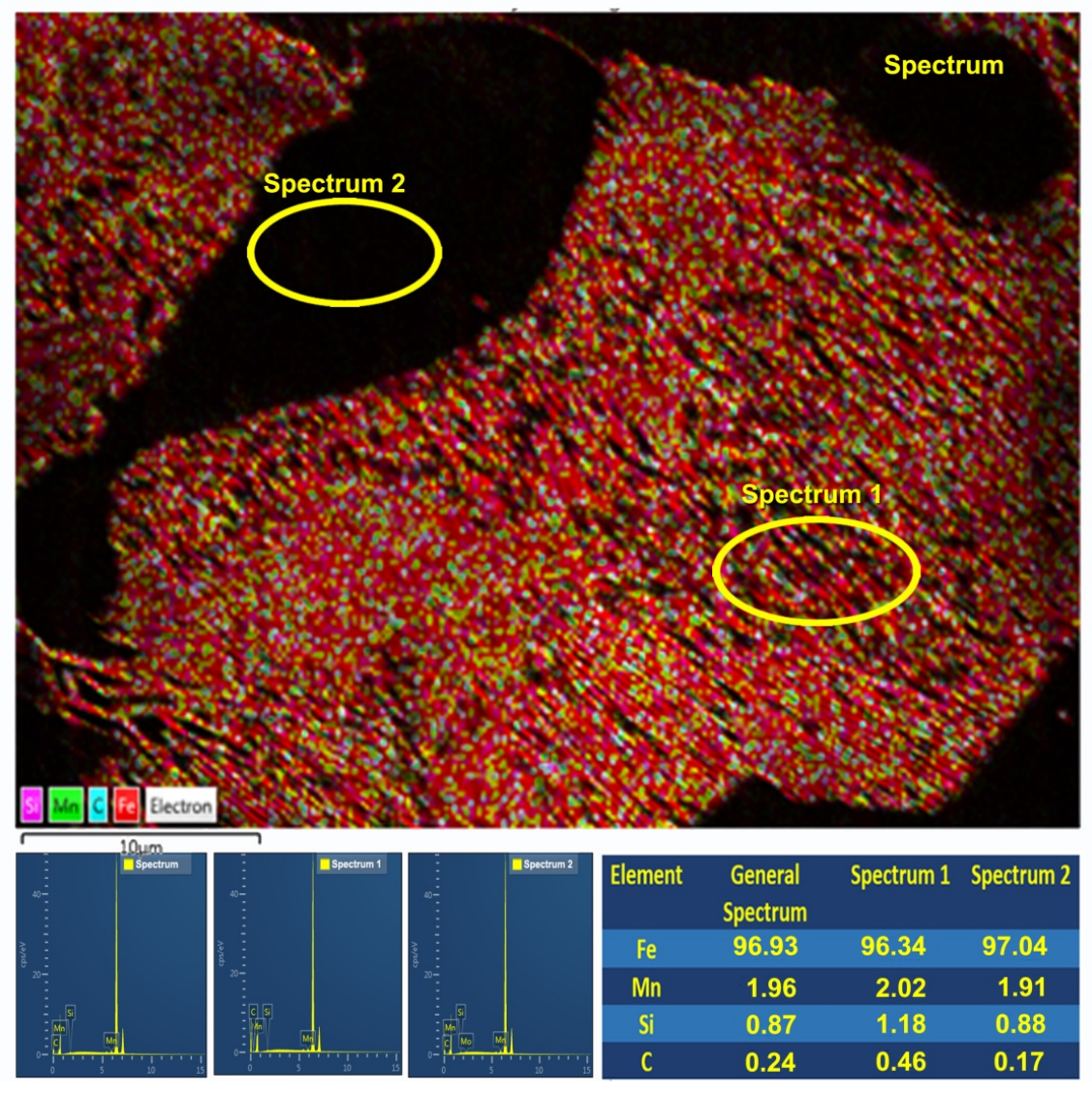


Fe K $\alpha 1$
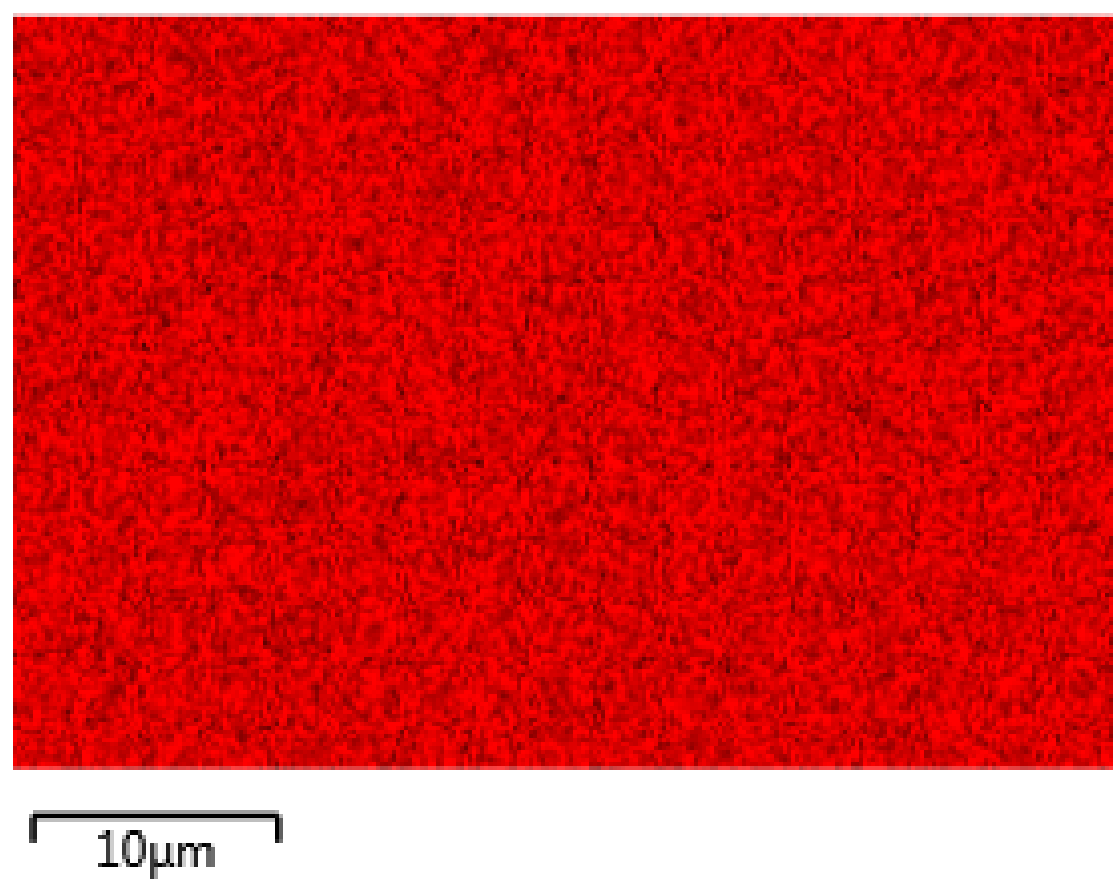

\section{Mn Ka1}

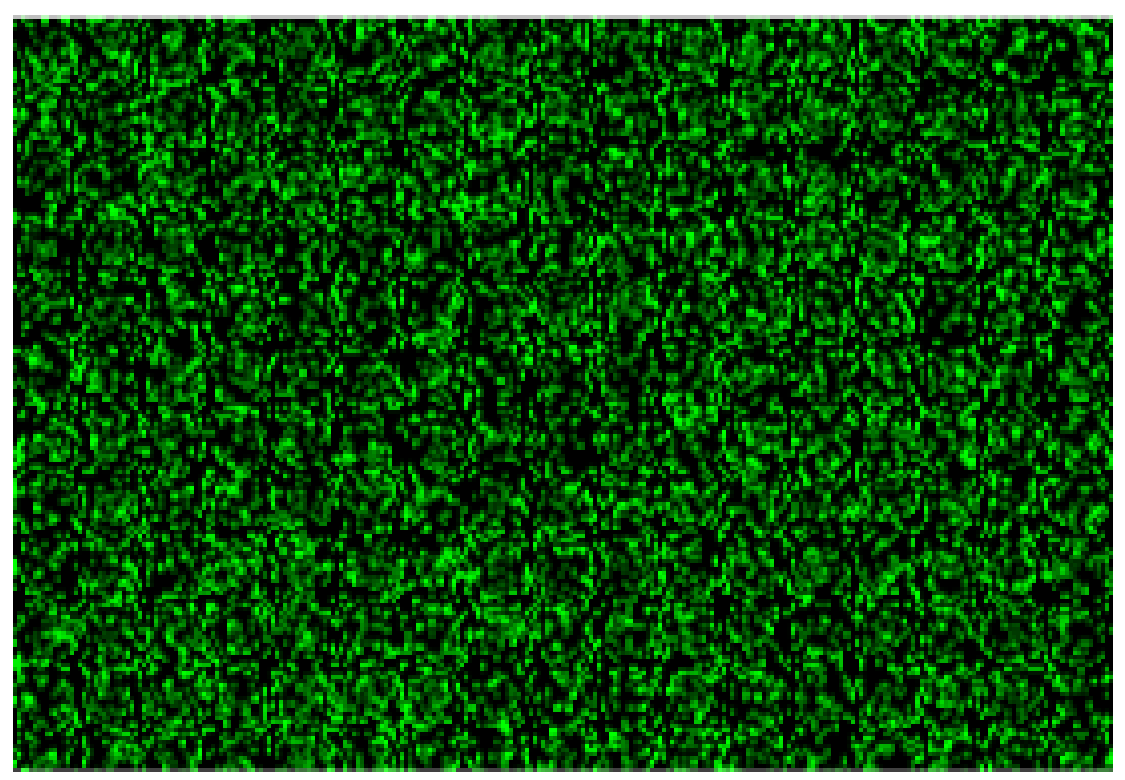

$$
10 \mu \mathrm{m}
$$


Si K $\alpha 1$

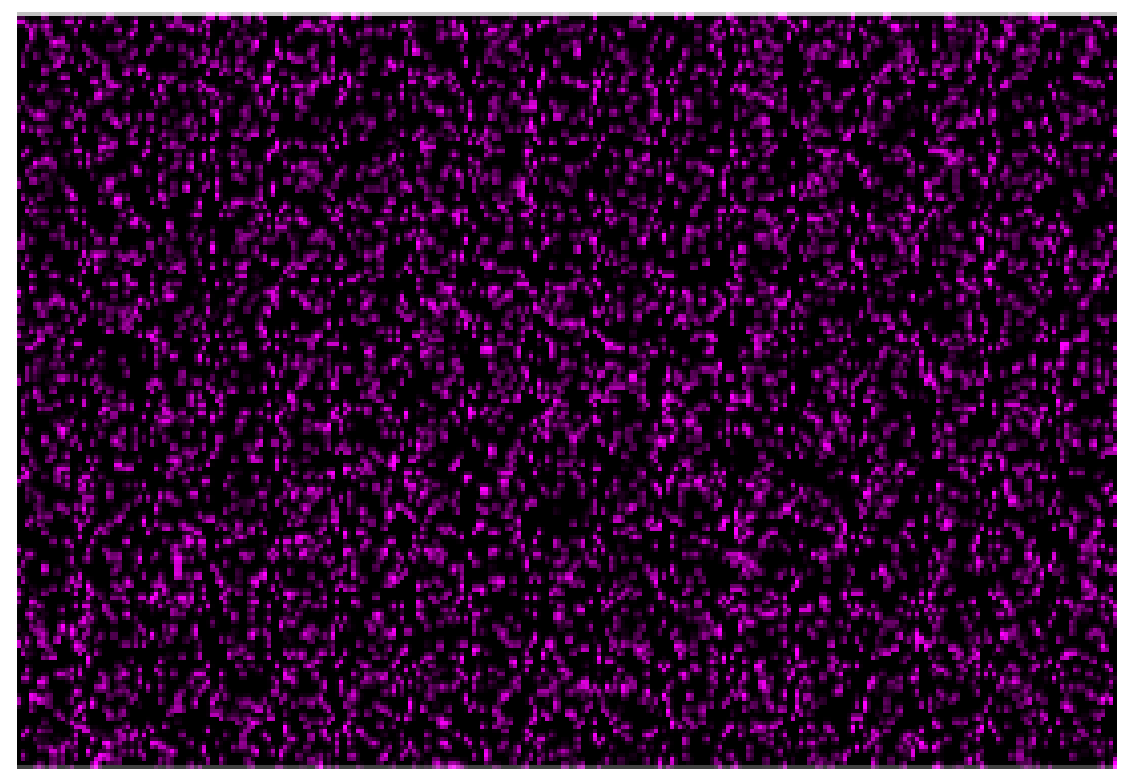

$10 \mu \mathrm{m}$

\section{Ka1_2}

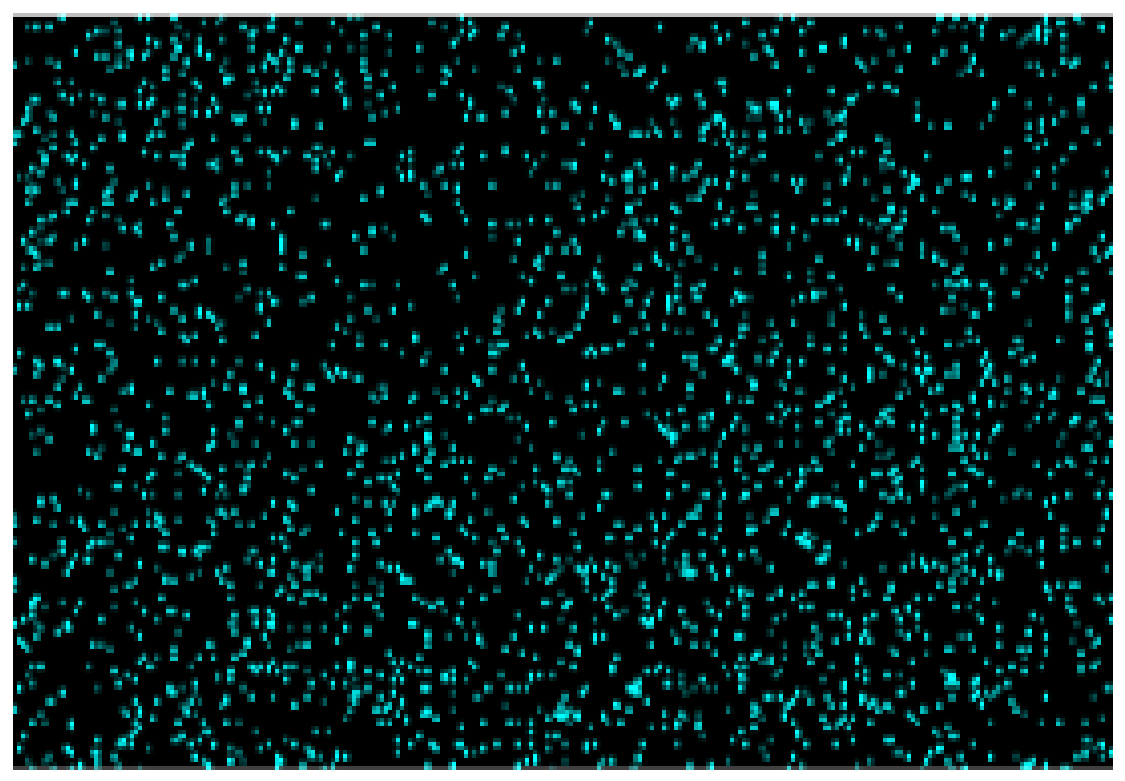

$$
10 \mu \mathrm{m}
$$


Figure 6. Numerical and graphical values of EDS analysis taken from the entire region or some parts of fracturing area of the bearing shell material.
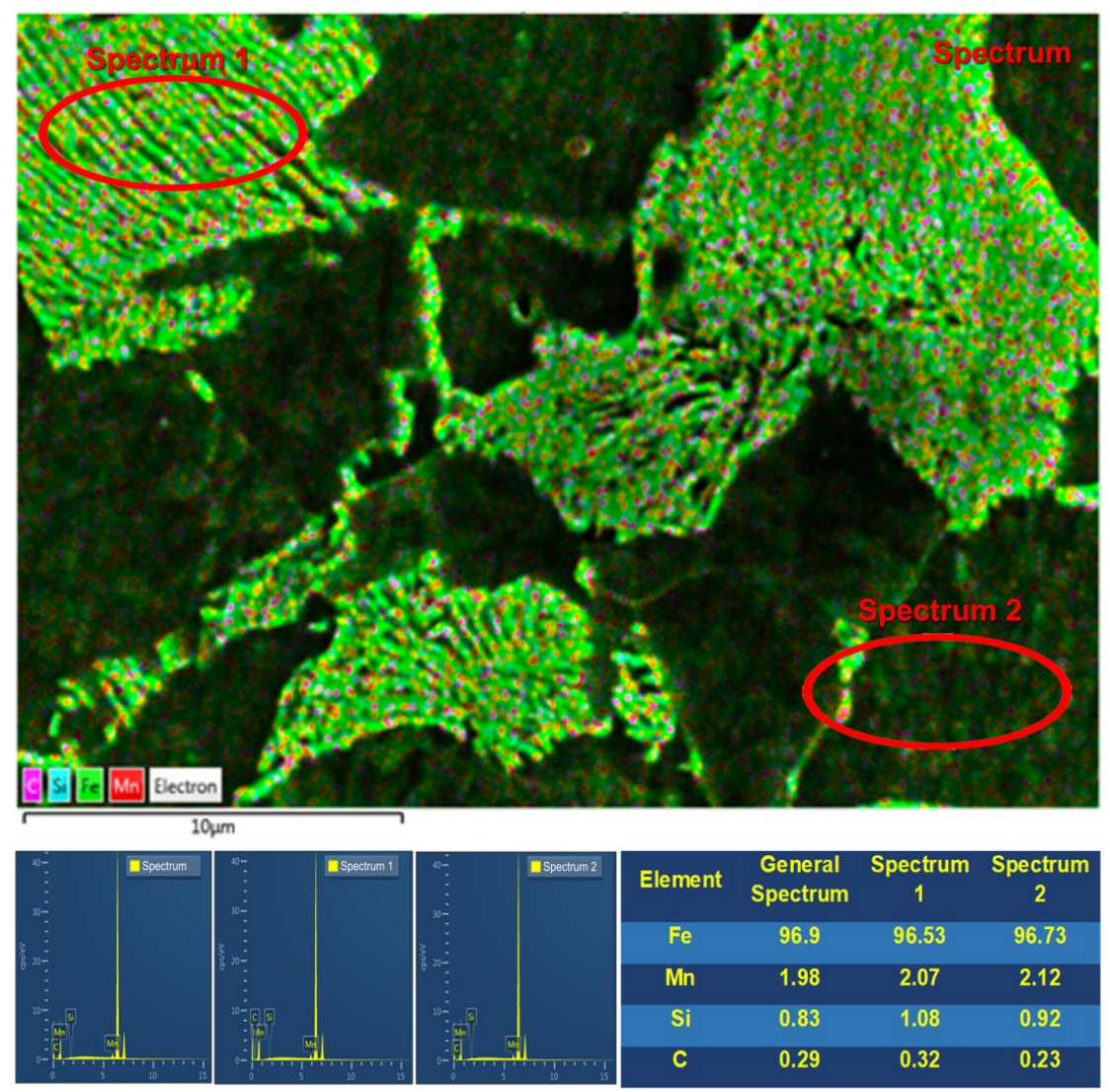

Figure 7. Numerical and graphical values of EDS analysis taken from the entire region or some parts of fracturing area of the bearing shell material

The generator guide bearing shell ring used in the shaft bearing is structurally low carbon steel. It is a material with low risk of fracturing due to its ductility. However, in order for the ring to be passed around the shaft tightly, heat is applied and the material is expanded. After the expanding ring is placed around the shaft, it is ensured that the material works together with the shaft as a result of contact with the shaft and cooling depending on the ambient conditions.

The bearing shell rings are made of large-sized parts so they cannot be subjected to heat treatment. Before mounting to the system, by using the oxyacetylene tubes the ring is heated by blowing the flame with the help of blowers. This cannot be applied to the entire ring at the same time but it is applied locally. Therefore, one region is exposed to heat while the other zone is not affected by heat. For this reason, dislocations occur in the locally heated part due to structural differences. Internal stresses in the material are thought to cause regional fractures. Fatigue is one of the most important reasons for the formation of fractures in materials that should not be ignored. The bearing shell ring can be exposed to varying loads in terms of operating conditions and may cause fracture formation due to prolonged use. 


\section{Conclusions}

Proper operation of turbine-generator bearings in hydroelectric power plants is of great importance for the unit to continue energy production. Therefore, it is necessary to periodically inspect the sliding bearings during the energy production by predictive maintenance methods and to measure and evaluate the factors such as vibration, balance and temperature. In this study, the causes of the fracture formed in the generator guide bearing shell of a hydroelectric power plant are investigated metallographically. When we examine the metallographic sample taken in the region near the fractured area near sliding bearing with the help of optical microscope, SEM images and EDS analysis, Ferrite and Perlite structures found in low carbon steels in the sample are seen and these structures have the least risk of fractures in the steel materials due to the formation of fractures So other factors that will affect the structure of this material have been focused. Variable loads and oil temperature changes as a result of this material working together with the shaft can cause fracture formation due to fatigue strength in the material. Not being able to apply necessary heat treatment in order to remove internal stresses that appear in the production stage of the ring when it becomes a cylinder due to the large size of ring causes fractures. Such fractures can occur frequently in the sliding bearing shells of hydroelectric power plants. The only way to prevent these fractures from damaging the sliding bearing is to follow the vibration changes in the bed well and to be interpreted by the experienced technical staff. Because vibration changes in sliding bearings can be caused by many reasons such as magnetic, dynamic and hydraulic imbalances.

\section{References}

1. M. Yücesan, G. Kahraman, Risk evaluation and prevention in hydropower plant operations: A model based on Pythagorean fuzzy AHP, Energy Policy, 2019, 126, 343-351. Doi : https://doi.org/10.1016/j.enpol.2018.11.039

2. I. Zidane, H. Zahloul, M. Hajjam, M. Abbadeni, Modeling and Analysis of the Slip Conditions in Hydrodynamic Lubrication, Arabian Journal for Science and Engineering, 2014, 39, 7199-7210. DOI 10.1007/s13369-014-1214-4

3. R. Goraj, Theoretical study on a novel electromagnetically supported hydrodynamic bearing under static loads, Tribology International, 2018, 119, 775-785. Doi : https://doi.org/10.1016/j.triboint.2017.09.021

4. L. Zoupas, M. Wodtke, C.I. Papadopoulos, M. Wasilczuk, Effect of manufacturing errors of the pad sliding surface on the performance of the hydrodynamic thrust bearing, Tribology International, 2019, 134, 211-220. Doi : https://doi.org/10.1016/j.triboint.2019.01.046

5. B. Manser, I. Belaidi, A. Hamrani, S. Khelladi, F. Bakir, Performance of hydrodynamic journal bearing under the combined influence of textured surface and journal misalignment: A numerical survey, Comptes Rendus Mécanique, 2019, 347, 2, 141-165. Doi : https://doi.org/10.1016/j.crme.2018.11.002

6. J.K. Paik, A.K., Thayamballi, J.M. Lee, Effect of initial deflection shape on the ultimate strength behavior of welded steel plates under biaxial compressive loads, J. Ship Res. 2004, 48, 1, 45-60.

7. J.K., Paik, Ultimate Limit State Analysis and Design of Plated Structures, John Wiley \& Sons, Chichester, UK, 2018

8. G. Da-wei, S. Gui-jie, W. De-ye, Residual ultimate strength of hull structures with fracture and corrosion damage, Eng. Fail. Anal., 2012, 25, 316-328. Doi : https://doi.org/10.1016/j.engfailanal.2012.05.003

9. Y. Hu, W. Cui, P.T., Pedersen, Maintained ship hull girder ultimate strength reliability considering corrosion and fatigue, Mar. Struct., 2004, 17, 2, 91-123. Doi : https://doi.org/10.1016/j.marstruc.2004.06.001

10. J.K., Paik, Residual ultimate strength of steel plates with longitudinal fractures under axial compressionexperiments, Ocean Eng., 2008, 35, 17, 1775-1783. Doi : https://doi.org/10.1016/j.oceaneng.2008.08.012

11. R. Seifi, N. Khoda-yari, Experimental and numerical studies on buckling of fractureed thin-plates under full and partial compression edge loading, Thin-Walled Struct., 2011, 49, 12, 1504-1516. Doi :https://doi.org/10.1016/j.tws.2011.07.010

12. J.K. Paik, Y.S. Kumar, J.M. Lee, Ultimate strength of fractureed plate elements under axial compression or tension, Thin-Walled Struct., 2005, 43, 2, 237-272.Doi : https://doi.org/10.1016/j.tws.2004.07.010

13. A. Babazadeh, M.R. Khedmati, Ultimate strength of fractureed ship structural elements and systems: a review, Eng. Fail. Anal., 2018, 89, 242-257. Doi : https://doi.org/10.1016/j.engfailanal.2018.03.003

14. R. Brighenti, Buckling of fractureed thin-plates under tension or compression, Thin-Walled Struct., 
2005, 43, 2, 209-224.Doi : https://doi.org/10.1016/j.tws.2004.07.006

15. J. Paik, A., Thayamballi, Ultimate strength of ageing ships, Proceedings of the Institution of Mechanical Engineers, Part M: J. Eng. Marit. Environ., 2002, 216, 1, 57-77. Doi : https://doi.org/10.1243/147509002320382149

16. P. Rycerz, A. Olver, A.Kadiric, Propagation of surface initiated rolling contact fatigue cracks in bearing steel. International Journal of Fatigue 97 (2017) 29-38 http://dx.doi.org/10.1016/j.ijfatigue.2016.12.004

17. S. Maya-Johnson, A.J. Ramirez, A. Toro . Fatigue crack growth rate of two pearlitic rail steels. Engineering Fracture Mechanics 138 (2015) 63-72. http://dx.doi.org/10.1016/j.engfracmech.2015.03.023

18. M.P. Valles, M.García, A.Pastor, Study of a torsion spring fracture, Eng. Fail. Anal., 2019, 98, 150-155. Doi : https://doi.org/10.1016/j.engfailanal.

19. A. Rahbar-Ranji, A. Zarookian, Ultimate strength of stiffened plates with a transverse fracture under uniaxial compression, Ships Offshore Struct., 2015, 10, 4, 416-425. Doi : https://doi.org/10.1080/17445302.2014.942078

20. Y. Prawoto, M. Ikeda, S.K. Manville, A. Nishikawa, Design and failure modes of automotive suspension springs, Eng. Fail. Anal., 2008, 15, 1155-1174 Doi : https://doi.org /10.1016/j.engfailanal.2007.11.003 